\title{
Three-dimensional numerical modeling of tsunami-related internal gravity waves in the Hawaiian atmosphere
}

\author{
Giovanni Occhipinti ${ }^{1,2}$, Pierdavide Coïsson ${ }^{1}$, Jonathan J. Makela ${ }^{3}$, Sébastien Allgeyer ${ }^{4}$, \\ Alam Kherani ${ }^{5}$, Hélène Hébert ${ }^{4}$, and Philippe Lognonné ${ }^{1}$ \\ ${ }^{1}$ Institut de Physique du Globe de Paris, Sorbonne Paris Cité, Univ Paris Diderot, UMR 7154 CNRS, F-94100 Saint Maur des Fossés, France \\ ${ }^{2}$ Office National d'Etudes et Recherches Aérospatiales, Palaiseau, France \\ ${ }^{3}$ Department of Electrical and Computer Engineering, University of Illinois at Urbana-Champaign, Urbana, Illinois, USA \\ ${ }^{4}$ CEA-DAM-DIF, F-91297 Arpajon, France \\ ${ }^{5}$ Instituto Nacional de Pesquisais Espaciais (INPE), Sao Jose dos Campos, Sao Paula, BR-12227010, Brazil
}

(Received April 8, 2011; Revised June 29, 2011; Accepted June 30, 2011; Online published September 27, 2011)

\begin{abstract}
The tremendous tsunami following the 2011 Tohoku Earthquake produced internal gravity waves (IGWs) in the neutral atmosphere and large disturbances in the overlying ionospheric plasma while propagating through the Pacific ocean. To corroborate the tsunamigenic hypothesis of these perturbations, we use a $3 \mathrm{D}$ numerical modeling of the ocean-atmosphere coupling, to reproduce the tsunami signature observed in the airglow by the imager located in Hawaii and clearly showing the shape of the modeled IGW. The agreement between data and synthetics not only supports the interpretation of the tsunami-related-IGW behavior, but strongly shows that atmospheric and ionospheric remote sensing can provide new tools for oceanic monitoring and tsunami detection. Key words: Internal gravity waves, tsunami, airglow, numerical modeling.
\end{abstract}

\section{Introduction}

After the 2004 Great Sumatra Earthquake and the consequent Indian Ocean Tsunami, the scientific community put its attention to alternative methods in oceanic monitoring to improve the response of tsunami detection and estimation.

Improvement of classic techniques, such as seismic source estimation (e.g., Ammon et al., 2006) and densification of the number of buoys in the oceans (González et al., 2005), was supported by a new effort in remote sensing: nominally the space-altimetry observation of the tsunami in the open sea (Okal et al., 1999; Smith et al., 2005) and the tsunami detection by ionospheric monitoring (Artru et al., 2005; Occhipinti et al., 2006). The recent devastating tsunamigenic earthquake occurred on 11 March, 2011, off the Pacific coast of Tohoku $\left(M_{\mathrm{w}}=9.3,05: 47: 32 \mathrm{UT}\right.$, $)$, indicating once again the importance of moving forward in this direction.

Several theoretical studies in the 1970s, including Hines's pioneering works on internal gravity waves (IGWs), suggested that atmospheric IGWs generated by a tsunami (Fig. 1) may well produce identifiable ionospheric signatures in the plasma (Hines, 1972; Peltier and Hines, 1976). In essence, during their upward propagation the IGWs are strongly amplified by the effect of the decrease of atmospheric density. The interaction of IGWs with the plasma at ionospheric heights produces strong variations in the plasma velocity and plasma density observable by iono-

Copyright (c) The Society of Geomagnetism and Earth, Planetary and Space Sciences (SGEPSS); The Seismological Society of Japan; The Volcanological Society of Japan; The Geodetic Society of Japan; The Japanese Society for Planetary Sciences; TERRAPUB.

doi:10.5047/eps.2011.06.051 spheric sounding.

The encouraging work of Artru et al. (2005) on the detection of the Peruvian tsunamigenic quake on 23 June, 2001 $\left(M_{\mathrm{w}}=8.4\right.$ at 20:33 UT) in the total electron content (TEC) measured by the Japanese dense GPS network, GEONET, opened the modern debate about the feasibility of tsunami detection by ionospheric sounding. The giant tsunami following the Sumatra-Andaman event $\left(M_{\mathrm{w}}=9.3,00: 58: 50\right.$ UT, 26 December, 2004, Lay et al., 2005), an order of magnitude larger than the Peruvian tsunami, provided worldwide remote sensing observations in the ionosphere, giving the opportunity to deeply explore ionospheric tsunami detection by ionospheric sounding (DasGupta et al., 2006; Liu et al., 2006a, b; Lognonné et al., 2006; Occhipinti et al., 2006, 2008b).

The theoretical and numerical work of Occhipinti et al. (2006) supported by TEC observation from the on-board altimeters Topex/Poseidon and Jason-1 quantitatively confirms the link between the ionospheric perturbation and the sea level displacement induced by the tsunami propagation.

Recent observational works highlight systematic ionospheric tsunami detection following several events with magnitude around 8 (Kuril 2006, Samoa 2009 and Chile 2010) utilizing GPS-derived TEC performed by moderatlysized networks, such as those on Hawaii (Rolland et al., 2010; Galvan et al., 2011).

Subsequent modeling studies estimate the role of the geomagnetic field in the tsunami signature at the $E$-region and $F$-region (Occhipinti et al., 2008a) as well as the detection possibility by over-the-horizon radar (Coïsson et al., 2011)

More recently, Hickey et al. (2010) have suggested that appreciable airglow modulations in the 630.0-nm intensity 

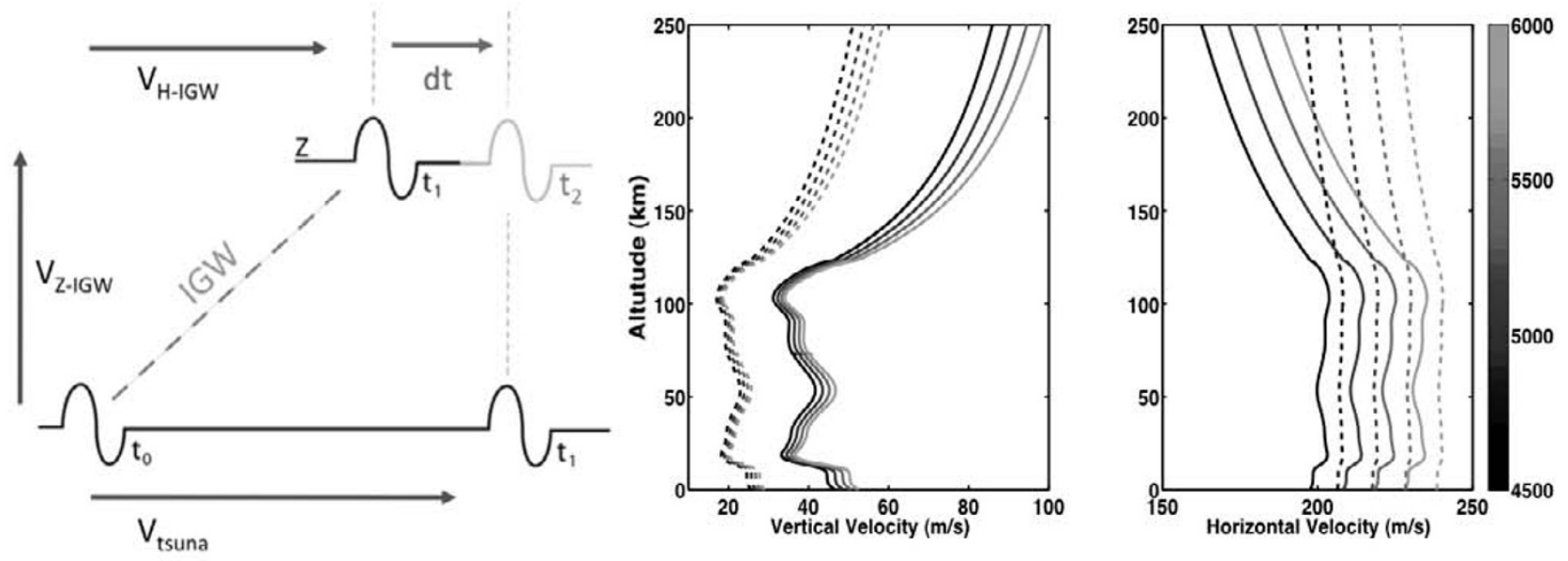

Fig. 1. Left: schematic representation of tsunami-related-IGW propagation with its vertical $V_{Z \text {-IGW }}=\frac{k_{z} k_{h}^{2} N^{2}}{\omega D^{2}}$ and horizontal $V_{H-\text { IGW }}=\frac{k_{h} N^{2}\left(D-k_{h}^{2}\right)}{\omega D^{2}}$ group velocities, where $k_{z}$ and $k_{h}$ are the vertical and horizontal $k$-vector, $g$ the gravity, $N$ the Brunt-Väisälä frequency and $D=k_{z}^{2}+k_{h}^{2}+\frac{N^{4}}{4 g^{2}}$. Following Occhipinti et al. $(2006,2008 \mathrm{a})$, we assume that the spatial and temporal dependency of wavefield is expressed in the form exp $\left(k_{x} x-k_{z} z-\omega t\right)$, where the dispersion equation take the form $\omega^{2} D=k_{h}^{2} N^{2}$. As $V_{H \text {-IGW }}$ is lower than the tsunami speed $V_{\text {tsuna }}=\sqrt{g H}$, the IGW accumulates a delay $(d t)$ with respect to the tsunami at the sea level during the upward propagation. The vertical and horizontal group velocity profiles for IGW of period $T_{1}=14$ minutes (solid lines) and $T_{2}=26$ minutes (dashed lines) are shown in the middle and right panel respectively; gray color indicates the speed dependence of ocean depth $H(\mathrm{~m})$. At the altitude of $250 \mathrm{~km}$ the delay $d t$ is on order of 6 min and 3 min for $T_{1}$ and $T_{2}$ respectively. An IGW needs around $80 \mathrm{~min}$ and $145 \mathrm{~min}$ to reach the altitude of $250 \mathrm{~km}$ for $T_{1}$ and $T_{2}$ respectively. Once the IGW reaches ionospheric altitude, the delay $d t$ between the IGW and tsunami wavefronts is constant during the oceanic propagation for a constant oceanic depth. The effect of the bathymetry variation can reduce, vanish or invert the delay $d t$.

should be expected. However, the first observations of this effect were not made until the 2011 Tohoku earthquake (Makela et al., 2011).

In this work, we model the IGW passing over Hawaii produced by the propagation of the Tohoku tsunami through the Pacific Ocean in order to reproduce the airglow observation measured by the ground-based camera located on the Haleakala Volcano on Maui, Hawaii (Makela et al., 2011).

\section{Modelling}

Following Occhipinti et al. (2006, 2008a) we compute, by three-dimentional numerical modeling, the atmospheric IGWs induced by the propagation of the 11 March 2011 tsunami in the overlying atmosphere. In essence, the IGW modeling is divided into two steps: first, we compute the tsunami propagation using a realistic bathymetry taking into account the Earth sphericity, then we compute the excited IGW in the neutral atmosphere in a cartesian coordinate system.

The ocean surface displacement is calculated using a finite difference scheme that resolves the hydrodynamical equations on a $30^{\prime \prime}$ bathymetric grid following Hébert et al. (2007). The input earthquake source consists of the USGS finite fault model (http://earthquake.usgs.gov/earthquakes).

Tsunami propagation is calculated through the whole Pacific Ocean every minute during the 12 hours following the earthquake.

The vertical velocity produced by the sea level displacement is used as input to the pseudo spectral propagator based on the linearised momentum and continuity equations, for irrotational, inviscid and incompressible flow (see Occhipinti et al. (2006, 2008a) for more details).

We propagate the IGW from the ocean surface to $250 \mathrm{~km}$,

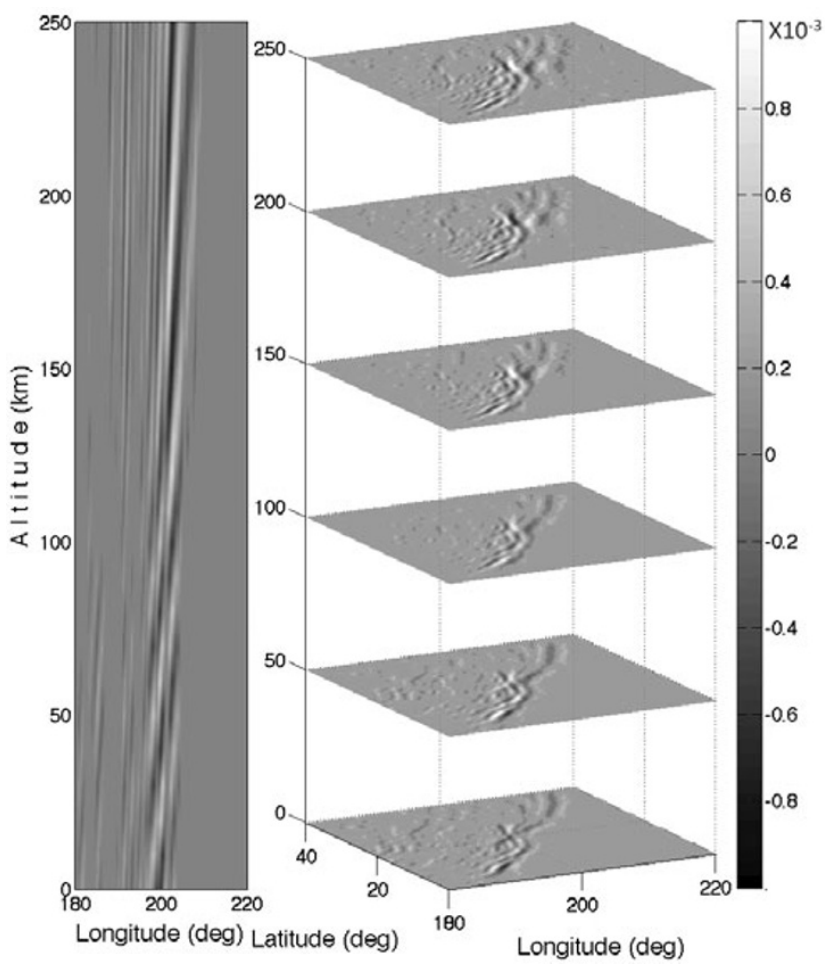

Fig. 2. IGW modeled normalized vertical velocity component of atmospheric wave motion in Hawaii region at 13:20 UT. Left: vertical cross section at $20^{\circ}$ latitude $\mathrm{N}$ clearly showing the inversion of the velocity component of IGW motion in a relative short distance; Right: horizontal cross sections from the bottom of the atmosphere up to $250 \mathrm{~km}$. The entire movie is available at www.ipgp.fr/ ninto/EPS/SMmovie.mov. 

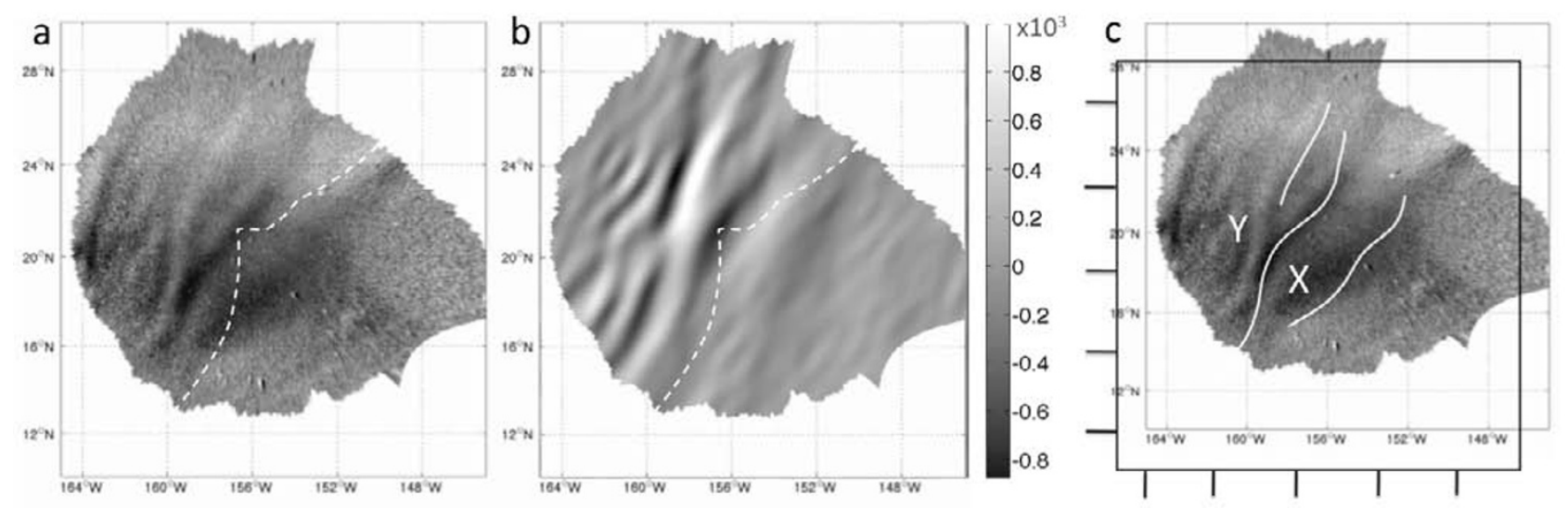

Fig. 3. (a) IGW imaged by the 630.0-nm ground-based airglow camera located on the Haleakala Volcano on Maui, Hawaii, at 13:20 UT. (b) normalized vertical velocity of the modeled IGW $\left(\left(\mathrm{kg} / \mathrm{m}^{3}\right)^{\frac{1}{2}} \mathrm{~m} / \mathrm{s}\right)$. The $\mathrm{Y}$ structure as well as the longer wavelength anticipating the $\mathrm{Y}(\mathrm{X})$ are present in both, airglow data and AGW synthetics. Those structures are observed between 12:12 to 13:32. The white dotted line in a and $\mathrm{b}$ shows the tsunami wavefront line at 13:20 UT. (c) graphical estimation of the shift induced by the wind between model and data: the grid and the white lines are estimated on $\mathrm{b}$, then shifted on a to fit with the position of $\mathrm{Y}$ and $\mathrm{X}$. The estimated shift of $2^{\circ}$ is coherent with previous observations (Occhipinti $e t$ al., 2006).
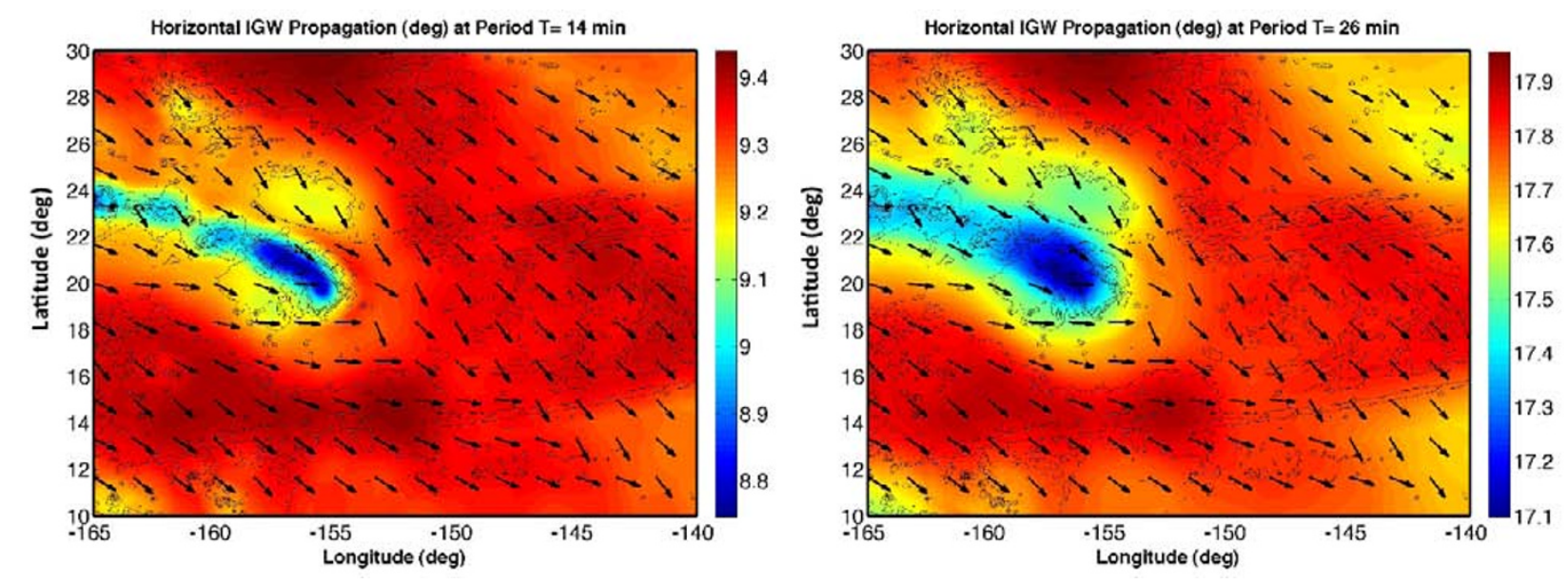

Fig. 4. Horizontal propagation distance (colorscale in degrees) and direction (arrows) covered by the IGW from the generation at the sea level to the altitude of $250 \mathrm{~km}$ at the main period of $14 \mathrm{~min}$ (left) and $26 \mathrm{~min}$ (right). In essence, the IGW generated at given position at the sea level will be observed at $250 \mathrm{~km}$ of altitude after covering a distance shown by the color and in the direction indicated by the arrow. The low bathymetry close to Hawaii reduces the horizontal velocity of the IGW and tsunami (Fig. 1), consequently IGW generated before Hawaii go beyond the IGW generated in the shallow bathymetry region as well as beyond the tsunami. This effect affects more the period at 26 min than 14 min.

which is the altitude at which the 630.0-nm airglow emission is assumed to be concentrated (e.g., Kelley et al., 2000; Makela and Kelley, 2003)

Attenuation effects, such as viscosity and thermal conduction, are neglected in our model as we are principally interested to the shape of the tsunami signature in the airglow data. Anyway, we highlight that their effect at $250 \mathrm{~km}$ of altitude reduces by a factor 5 the amplitude of the IGWs (Hickey et al., 2009).

We focus the analysis in the Hawaii region, in a geographic grid between $0^{\circ}$ and $40^{\circ}$ latitude $\mathrm{N}$ and $180^{\circ}$ and $220^{\circ}$ longitude E. According to the modeling, the tsunami was crossing this region between $11 \mathrm{UT}$ and $15 \mathrm{UT}$ with a maximum wave amplitude of about $10-15 \mathrm{~cm}$ in the open ocean. Figure 2 shows the IGW model results at 13:20 UT with a well defined structure of gravity wave propagation.
The IGW is traveling through this area southeastwards with its wave front being in the SW-NE direction. The retarding effect of the Hawaii archipelago can be appreciated at the center of the horizontal cross-section.

As the bathymetry variation also affects the vertical and horizontal IGW group velocities (Figs. 1 and 4), the lowbathymetry close to Hawaii affects the propagation of the tsunami-related IGW. Additionally, vertical and horizontal IGW group velocities are strongly dependent on the dominant period of the tsunami at sea level. Two main periods have been observed after analyzing the Deep-ocean Assessment and Reporting of Tsunamis (DART) data: 14 min and 26 min (Makela et al., 2011).

As a consequence of the combined effect of the period and the bathymetry on the IGW group velocities, the IGWs generated before the interaction with the Hawaiian 
archipelagos and the Hawaiian-Emperor seamount chain, go beyond the tsunami wave front during their propagation in the atmosphere.

This effect is visible in the vertical cross-section of the IGW close to Hawaii (Fig. 2) as well as on the IGW propagating at $250 \mathrm{~km}$ of altitude, clearly highlighting the differentiation link to the period (Fig. 3(a-b)): the longer wavelength IGW (indicated by the X in Fig. 3 ) is over the tsunami wavefront where the shorter wavelength IGW with the "Y" shape stay behind the tsunami wavefront. We note that this effect is also visible in the airglow data (Fig. 3(a)).

\section{Comparison with Hawaiian Airglow Observa- tion}

The tsunami reached Hawaii during the night hours with a predominantly clear sky, optimal conditions to detect the expected IGWs by optical sensors. The highly sensitive, wide-angle camera system located atop the Haleakala Volcano on Maui, Hawaii, was able to record the airglow emission at $630.0 \mathrm{~nm}$ with a temporal resolution of approximately 5 minutes during the time when the tsunami was crossing that area. The spatial coverage of the observation is approximately $10^{6} \mathrm{~km}^{2}$ in the ionosphere at the assumed emission altitude of $250 \mathrm{~km}$. The 630.0-nm airglow emission is produced by the dissociative recombination of $\mathrm{O}_{2}^{+}$ (Link and Cogger, 1988) and is sensitive to both changes in the electron and neutral densities.

Comparison between the modeled IGW and the airglow observation in Fig. 3 shows several interesting likenesses explaining the nature of the airglow observation:

The Y shape presents in our IGW modeling is also recognizable in the data, this is clear evidence of the tsunami nature of the airglow observation. Additionally, we highlight a longer wavelength signal $(\mathrm{X})$ in both airglow data and IGW modeling, arriving before the Y curved feature and also before the tsunami arrival time (white dotted line). This effect has been detailed in the previous section and is the consequence of the low bathymetry around Hawaii.

The $\mathrm{Y}$ curved feature also allows us to quantify the shift of $2^{\circ}$ between airglow data and the synthetic IGW (Fig. 3(c)). A similar shift was observed by Occhipinti et al. (2006) in comparison between altimeters-TEC data and synthetics, and is most likely due to the zonal and meridional wind neglected in our modeling.

\section{Conclusions}

The tremendous tsunami following the 11 March 2011 Tohoku mega-quake generated a huge amount of data all around the Pacific Ocean. This event particularly highlight, for the first time, the possibility to detect tsunami relate IGW with the ground-based airglow camera located in Hawaii (Makela et al., 2011).

The observed airglow signal presents several questions and uncertainties that are explored here with the support of the three-dimensional modeling of the tsunami related IGW propagating in the atmosphere overlying the Hawaiian archipelagos.

The comparison with the modeling, first, highlights the tsunamic nature of the airglow data by the characteristic "Y" shape appearing in both synthetics and data; second, it explains the anticipated signal arriving before the tsunami front-wave, and finally, it allows quantification of the shift of $2^{\circ}$ mainly due to the wind effect.

This preliminary result motivate the development of a full modeling of the airglow observation taking into account, not only the wind, but above all the different ionized species taking part in the formation of the airglow signal, as well as the observational geometry of the ground-based camera.

Waiting for a full airglow modeling, the effort of this preliminary work highlights that remote sensing of tsunamis via the atmospheric/ionospheric monitoring by groundbased or on-board camera is a mature technique for oceanic monitoring and can take a role in the future of tsunami detection.

Acknowledgments. This project is supported by the CNES, and PNTS/INSU. This work has been supported by the French Space Agency CNES and by the Unite States Office of Naval Research (ONR) Global under contract IONONAMI-N07-25. Work at the University of Illinois was supported by the United States Office of Naval Research (ONR) through grant N00014-09-1-0439 and the National Science Foundation through grant ATM 06-44654 CAR. We thank Dr R. McCoy for fruitful discussion and bridging the US and French groups. We thank M. Hickey and an anonymous reviewer for their accurate and constructive remarks. This is IPGP contribution 3180 .

\section{References}

Ammon, C. J., A. A. Velasco, and T. Lay, Rapid estimation of first-order rupture characteristics for large earthquakes using surface waves: 2004 Sumatra-Andaman earthquake, Geophys. Res. Lett., 33, L14314, 2006. Artru, J., V. Ducic, H. Kanamori, P. Lognonné, and M. Murakami, Ionospheric detection of gravity waves induced by tsunamis, J. Geophys. Res., 160, 840, 2005.

Coïsson, P., G. Occhipinti, P. Lognonné, J. P. Molinie, and L. M. Rolland, Tsunami signature in the ionosphere: the innovative role of OTH radar, Radio Sci., 2011 (under revision).

DasGupta, A., A. Das, D. Hui, K. K. Bandyopadhyay, and M. R. Sivaraman, Ionospheric perturbation observed by the GPS following the December 26th, 2004 Sumatra-Andaman earthquake, Earth Planets Space, 35, 929-959, 2006.

Galvan, D. A., A. Komjathy, M. P. Hickey, and A. J. Mannucci, The 2009 Samoa and 2010 Chile tsunamis as observed in the ionosphere using GPS total electron content, J. Geophys. Res., 116, A06318, doi:10.1029/2010JA016204, 2011

González, F. I., E. N. Bernard, C. Meinig, M. C. Eble, H. O. Mofjeld, and S. Stalin, The NTHMP tsunameter network, Nat. Hazards, 35, 25-39, 2005.

Hébert, H., A. Sladen, and F. Schindelé, The great 2004 Indian Ocean tsunami: numerical modeling of the impact in the Mascarene Islands, Bull. Seismol. Soc. Am., 97(1A), S208-S222, 2007.

Hickey, M. P., G. Schubert, and R. L. Walterscheid, The Propagation of Tsunami-Driven Gravity Waves into the Thermosphere and Ionosphere, J. Geophys. Res., 114, A08304, doi:10.1029/2009JA014105, 2009.

Hickey, M. P., G. Schubert, and R. L. Walterscheid, Atmospheric airglow fluctuations due to a tsunami-driven gravity wave disturbance, J. Geophys. Res., 115, A06308, doi:10.1029/2009JA014977, 2010.

Hines, C. O., Gravity waves in the atmosphere, Nature, 239, 73-78, 1972. Kelley, M. C., F. J. Garcia, J. Makela, T. Fan, E. Mak, C. Sia, and D. Alcocer, Highly structured tropical airglow and TEC signatures during strong geomagnetic activity, Geophys. Res. Lett., 27(4), 465-468, 2000.

Lay, T., H. Kanamori, C. J. Ammon, M. Nettles, S. N. Ward, R. C. Aster, S. L. Beck, S. L. Bilek, M. R. Brudzinski, R. Butler, H. R. DeShon, G. Ekstrom, K. Satake, and S. Sipkin, The great Sumatra-Andaman earthquake of 26 December 2004, Science, 308, 1127-1133, 2005.

Link, R. and L. L. Cogger, A reexamination of the O I 6300-Å nightglow, J. Geophys. Res., 93(A9), 9883-9892, 1988.

Liu, J. Y., Y. B. Tsai, S. W. Chen, C. P. Lee, Y. C. Chen, H. Y. Yen, W. Y. Chang, and C. Liu, Giant ionospheric distrubances excited by the M9.3 Sumatra earthquake of 26 December 2004, Geophys. Res. Lett., 33, L02103, doi:10.1029/2005GL023963, 2006a. 
Liu, J., Y. Tsai, K. Ma, Y. Chen, H. Tsai, C. Lin, M. Kamogawa, and C. Lee, Ionospheric GPS total electron content (TEC) disturbances triggered by the 26 December 2004 Indian Ocean tsunami, J. Geophys. Res., 111, A05303, doi:10.1029/2005JA011200, 2006b.

Lognonné, P., J. Artru, R. Garcia, F. Crespon, V. Ducic, E. Jeansou, G. Occhipinti, J. Helbert, G. Moreaux, and P. E. Godet, Ground based GPS imaging of ionospheric post-seismic signal, Planet. Space Sci., 54, 528$540,2006$.

Makela, J. J. and M. C. Kelley, Using the 630.0-nm nightglow emission as a surrogate for the ionospheric Pedersen conductivity, J. Geophys. Res., 108(A6), 1253, doi:10.1029/2003JA009894, 2003.

Makela, J. J., P. Lognonné, H. Hébert, T. Gehrels, L. Rolland, S. Allgeyer, A. Kherani, G. Occhipinti, E. Astafyeva, P. Coïsson, A. Loevenbruck, E. Clévédé, M. C. Kelley, and J. Lamouroux, Imaging and modelling the ionospheric response to the 11 March 2011 Sendai Tsunami over Hawaii, Geophys. Res. Lett., 2011 (accepted).

Occhipinti, G., P. Lognonné, E. Alam Kherani, and H. Hébert, Threedimensional waveform modeling of ionospheric signature induced by the 2004 Sumatra tsunami, Geophys. Res. Lett., 33, L20104, doi:10. 1029/2006GL026865, 2006.

Occhipinti, G., E. Alam Kherani, and P. Lognonné, Geomag- netic dependence of ionospheric disturbances induced by tsunamigenic internal gravity waves, Geophys. J. Int., doi:10.1111/j.1365246X.2008.03760.x, 2008a.

Occhipinti, G., A. Komjathy, and P. Lognonné, Tsunami detection by GPS: how ionospheric observation might improve the Global Warning System, GPS World, 50-56, Feb., 2008b.

Okal, E. A., A. Piatanesi, and P. Heinrich, Tsunami detection by satellite altimetry, J. Geophys. Res., 104, 599-615, 1999.

Peltier, W. R. and C. O. Hines, On the possible detection of tsunamis by a monitoring of the ionosphere, J. Geophys. Res., 81(12), 1995-2000, 1976.

Rolland, L., G. Occhipinti, P. Lognonné, and A. Loevenbruck, The 29 September 2009 Samoan tsunami in the ionosphere detected offshore Hawaii, Geophys. Res. Lett., 37, L17191, doi:10.1029/2010GL044479, 2010.

Smith, W., R. Scharroo, V. Titov, D. Arcas, and B. Arbic, Satellite altimeters measure Tsunami, Oceanography, 18(2), 11-13, 2005.

G. Occhipinti (e-mail: ninto@ipgp.fr), P. Coïsson, J. J. Makela, S. Allgeyer, A. Kherani, H. Hébert, and P. Lognonné 